\title{
Lateral Supraorbital Craniotomy for Tuberculum Sella Meningioma Resection
}

\author{
Georgios Klironomos ${ }^{1}$ Neal Mehan ${ }^{1} \quad$ Amir R. Dehdashti ${ }^{1}$ \\ 1 Department of Neurosurgery, North Shore University Hospital, \\ Hofstra Northwell School of Medicine, Manhasset, New York, \\ United States

\begin{abstract}
Address for correspondence Amir R. Dehdashti, MD, Department of Neurosurgery, North Shore University Hospital, Hofstra Northwell School of Medicine, 300 Community Drive, Manhasset, NY 11030,
\end{abstract} \\ United States (e-mail: adehdashti@northwell.edu).
}

J Neurol Surg B 2018;79(suppl S3):S263-S264.

\begin{abstract}
Keywords

- suprasellar tumors

- lateral supraorbital craniotomy

- meningioma

Tuberculum sella meningioma can be approached by either open or endoscopic approaches. The aim of this video case presentation is to highlight the nuances of the lateral supraorbital craniotomy for tuberculum sella meningioma resection. The authors present a 34-year-old female patient who presented with decreased right eye visual acuity (20/60), afferent pupillary defect, and nasal field cut due to a tuberculum sella meningioma. The tumor was partially encasing the left A1 artery, severely displacing the optic apparatus, and minimally invading the right optic canal. The lateral supraorbital craniotomy was considered the most suitable approach to this tumor. The operative nuances and pitfalls of this approach are detailed in the video. Gross total resection of the tumor was achieved and confirmed with postoperative MRI. The patient's vision gradually improved and she was discharged on the fourth postoperative day. The minimally invasive lateral supraorbital craniotomy for tuberculum sella meningioma is a suitable approach in selected cases.

The link to the video can be found at: https://youtu.be/yG8q6YH2D9k.
\end{abstract}

Conflict of Interest

None.

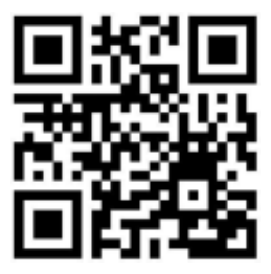

received

October 15, 2017 accepted

December 7, 2017

published online

February 14, 2018 www.thieme.com/skullbasevideos

www.thieme.com/jnlsbvideos
DOI https://doi.org/

10.1055/s-0038-1623530. ISSN 2193-6331.
๑) 2018 Georg Thieme Verlag KG
Stuttgart · New York

License terms

(ㄷ) (i) $\ominus$ (8) 

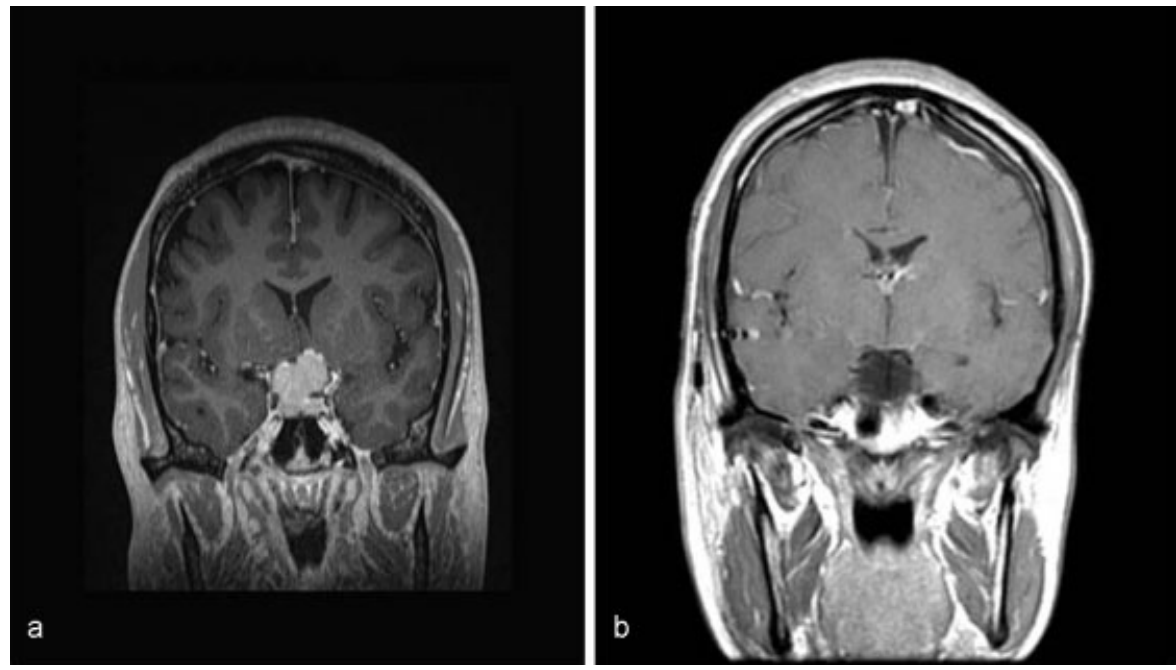

Fig. 1 (a) Coronal MRI with GAD showing a tuberculum sella meningioma. (b) Post operative MRI confirmed gross total resection of the tumor.

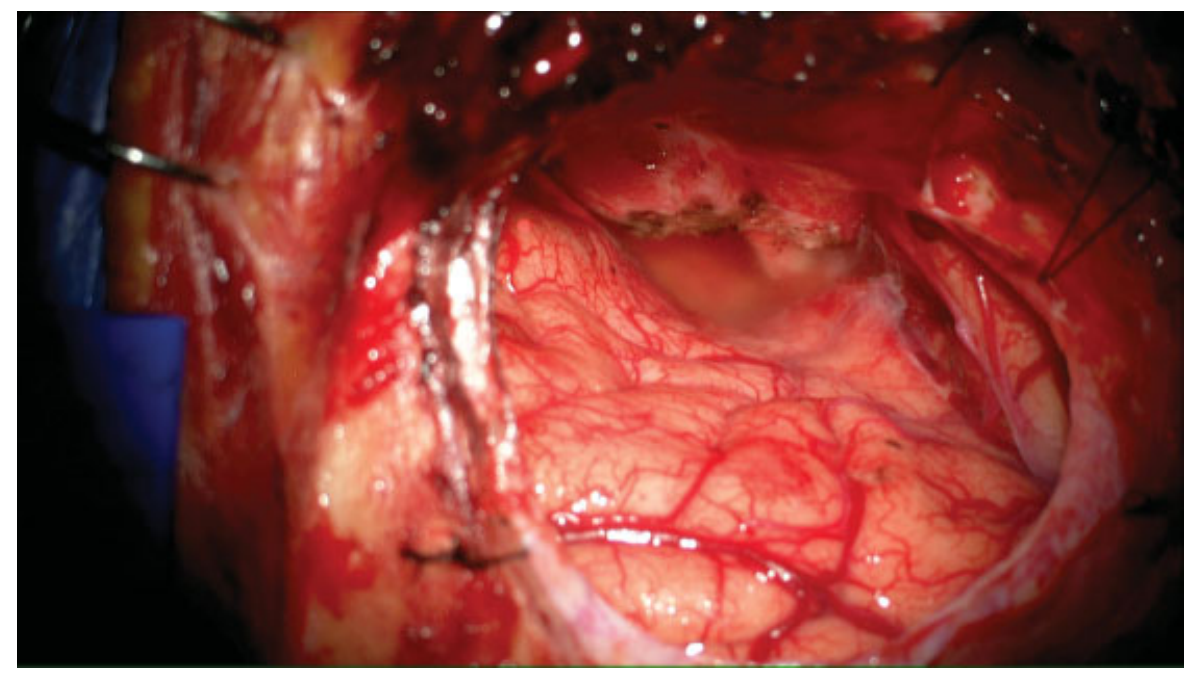

Fig. 2 Operative photo at the end of the procedure showing dura opening. 